REVIEW

\title{
Nutrition in the 21 st century: what is going wrong
}

\author{
R J Harris
}

Arch Dis Child 2004;89:154-158. doi: 10.1136/adc.2003.019703

\section{"Things sweet to taste prove in digestion sour" (Shakespeare, Richard II, Act 1, Scene 3, line 236)}

O ver the past 20 years there has been increasing interest in the central role of nutrition in growth and development. Much of the research has been around the issue of very long chained polyunsaturated fatty acids (LCPUFA) in the diet and the effect on brain development.

Much of the work, however, has been done in the neonatal period, but little has been done to continue the lessons learned into infancy and childhood.

Many children in western societies now live on carbohydrate rich, nutritionally inappropriate food. This, together with a rising fat intake has led to increasing numbers of obese children, and an epidemic of chronic iron deficiency, particularly in many inner city areas. Rickets, too, makes a frequent and unwelcome appearance today, despite government recommendations concerning vitamin supplementation to infants and young children.

Little impact is being made on the major nutritional problems affecting children in the first few years of life, most especially in inner city areas in the UK, when poor nutrition and iron deficiency can have profound and long lasting effects on both growth and development. Inner cities, particularly those with large Asian communities, have an unacceptable degree of chronic iron deficiency in the under $5 \mathrm{~s}$, as well as other diseases of malnutrition such as rickets.

Paediatricians are starting to see an increase in obesity related disorders such as type II diabetes, polycystic ovary syndrome, hirsutism, sleep disorders, joint pains, etc.

Of course, nothing in the UK can compare with the horrors of the gross malnutrition and starvation affecting large parts of the globe, but that malnutrition is a problem still in one of the wealthiest countries in the world is of major concern.

Although there are many other areas of deficiencies of concern in this country, in this review I will concentrate specifically on the role of LCPUFA, some of the problems of our inner cities, and the possible implications for the future health of the nation.

\section{NEONATAL NUTRITION}

This is the area in which there has been most research, in particular the role of LCPUFA in the growth and development of preterm and low birth weight infants.

The real relevance of breast milk and growth and development has been clouded by claims that breast fed babies are more intelligent than formula fed babies-a claim that in the 1980s led to tabloid headlines on the subject. Although there are many articles claiming an advantage for breast milk, critical analysis has revealed flaws in many of the articles. ${ }^{1}$ Despite these flaws, there is increasingly compelling evidence that breast feeding does impart advantages in cognitive development in both preterm and term infants. ${ }^{2}{ }^{3}$

For many years neonatologists had argued that the best milk for a preterm baby was breast milk. Until the anxieties about HIV and AIDS in the 1980s, many neonatal intensive care units had breast milk banks and routinely fed preterm babies milk from this source if the mother was unable to provide any breast milk. It was always noted, however, that preterm babies fed exclusively on bank breast milk did not seem to gain weight particularly quickly; ${ }^{4}$ and supplementation of breast milk, ${ }^{5}$ and later the provision of high energy feeding for the low birth weight baby became the normal procedures in many neonatal units. However, supplementation of breast milk is very imprecise, mainly because of the almost daily changes in breast milk composition; accordingly the amount of fortification needed would vary daily. ${ }^{6}$ Furthermore, premature babies fed fortified breast milk still do not gain weight as rapidly as those fed on preterm infant formulae. ${ }^{7}$ However, although the evidence is at times conflicting, the feeding of fortified human milk offers more advantages to the preterm infant than disadvantages, and ideally should be the normal practice in neonatal units. $^{8}$

There has been much debate around the timing of the onset of feeding, mainly because of anxieties about necrotising enterocolitis (NEC). However, there is no evidence that early feeding is associated with an increase in NEC, and furthermore a gut deprived of feeding leads to decreased intestinal motility, intestinal mucosal atrophy, and a longer time to establish enteral nutrition. However, NEC is less common in babies fed human milk, and there is evidence that hypocaloric feeds of human milk for the first week or two of life encourages postnatal intestinal adaptation ${ }^{10}$ and results in less jaundice, osteopenia of prematurity, and earlier establishment of full enteral feeds. ${ }^{11}$ For optimal growth and development of premature infants, a week or 
two of hypocaloric human milk feeding to start with, followed by enteral feeds with premature infant formula appears to offer the best compromise. ${ }^{12}$

The exact role of LCPUFA on growth and development remains unclear, but many issues are becoming more clarified. The long chained polyunsaturated fatty acids are arachidonic and docosahexanoic (DHA) acids (known as $\omega$-3 fatty acids). During early life, LCPUFA are incorporated in large amounts, particularly in the non-myelin parts of the central nervous system and in the retina. ${ }^{13}$ The LCPUFA are precursors of eicosanoids, which are molecules with wide ranging biological activity that effectively control many cellular processes. ${ }^{14}$

Early animal work using a diet low in $\alpha$-linolenic acid (a precursor of DHA) showed impaired learning, ${ }^{15}$ and it is also known that LCPUFA are preferentially accumulated by the infant brain during the last trimester of pregnancy. ${ }^{16}$ LCPUFA are present in breast milk, but until relatively recently were not added to infant formulae. However, it is known that the enzyme systems necessary to convert the essential fatty acids linoleic and $\alpha$-linolenic acids to LCPUFA are reduced in the preterm infant. ${ }^{13}$ As a result of this knowledge, LCPUFA became added to premature infant formulas.

The development and growth of infants fed LCPUFA enriched formula has been looked at in many studies. Results tend to be a little confusing. However, randomised studies have shown positive effects on the development of the visual system in preterm infants, ${ }^{17}$ but less so in term infants. $^{18}$ However, supplementing term infants with LCPUFA did seem to result in more effective problem solving (finding a hidden toy) than in those not fed supplemented formula. ${ }^{19}$ However, other surveys have suggested that the effect is only transient, ${ }^{20}$ or there is no effect at all. ${ }^{21}$ Two fairly recent studies have suggested opposite effects. One study in term infants showed significantly higher scores on the Bayley Mental Development Index in infants supplemented with LCPUFA until 17 weeks of age, ${ }^{22}$ whereas another study found no benefit at all. ${ }^{23}$ Interestingly, some studies have suggested that babies fed formula fortified with LCPUFA do not grow as well as those not fed supplemented formula. ${ }^{24}$

Although some of the evidence is conflicting, metaanalysis has shown overall more mature sight skills and a higher IQ in babies fed breast milk; this is probably attributable to the LCPUFA. ${ }^{25}$ Addition of LCPUFA to formula has been shown to be safe, and so the balance of opinion is in favour of the advantages in term infants; as a consequence all specialised milks for low birth weight babies and the standard infant formulas have LCPUFA added.

\section{WHERE HAS IT ALL GONE WRONG?}

Nowadays, with the evidence accumulated from the studies in the newborn infants, most infants in the UK at least have the opportunity to have every early advantage. However, what goes wrong during early infancy and childhood that leads to all the problems currently seen in inner cities?

\section{INNER CITY PROBLEMS}

A common complaint in many paediatric units, child health clinics and general practitioner surgeries, particularly in inner city areas with high levels of deprivation and poorer social class, is the complaint that a child is not eating. These socalled "not eating" children are usually eating crisps or some other snack foods, or have a bottle of milk permanently clamped between their lips. The parents will complain that they vomit solid food, or cannot chew any food at all. They scream if the bottle is taken away, and a significant number of them will be iron deficient.
By the age of 12 months all babies should be able to take drinks from cups. However, it is easier to give a toddler a bottle and let him/her feed that way. If cups could be used more widely, then the amount of milk drunk would inevitably be reduced. In any city shopping centre, children of 3 and 4 years of age will be seen with a bottle of milk or juice suspended from their mouth. They constantly drip feed themselves and as a result do not feel hungry and refuse to eat, unless offered crisps or sweets. Efforts have been made around the country on "bottle to cup" campaigns to try and break this almost universal habit, with some evidence of success. ${ }^{26}$ There needs to be a nationwide advertising campaign to reinforce the advantages of cup or beaker feeding.

Iron deficiency is a major problem in children in the first two years of life in inner city areas, especially in those from the Asian community. Much of this is related to a poor food intake, the early introduction of whole cows' milk, and a high intake of fruit juice, often seen as a consequence of late weaning.

\section{Weaning problems}

Earlier work in Tower Hamlets revealed a high rate of late weaning. ${ }^{27}$ Figure 1 illustrates the time of weaning in a sample of infants from two ethnic groups in Tower Hamlets. Recent work (unpublished) has confirmed that the problem of late and delayed weaning has persisted.

It is well established that weaning tends to be later in Asian children living in inner cities in the UK. ${ }^{28}$ Delayed weaning causes problems later with differing tasting food and coping with lumps, ${ }^{29}$ mainly because the baby has missed out on the critical phases of developing taste from 46 months and establishing the ability to cope with lumps from 6-8 months. As a result, they exist on bland, non-lumpy food, and will have carbohydrate rich, bland foods in the diet. Because they have not been given food, milk is continued. ${ }^{30}$ It has also been suggested that such children may have language delay. Recent work shows that the average milk intake of a sample of Bangladeshi infants at 18 months of age is $600 \mathrm{ml}$. The Department of Health recommendation is $300 \mathrm{ml}$ at 1 year. ${ }^{31}$

\section{Iron deficiency}

The WHO has suggested levels of haemoglobin below which anaemia is said to be present. These levels are $<110 \mathrm{~g} / \mathrm{l}$ in children aged $1-2$ years of age and $<112 \mathrm{~g} / \mathrm{l}$ in children aged $3-5$. Although it has been suggested that this is too high a figure, it is the one on which figures are based. Using these

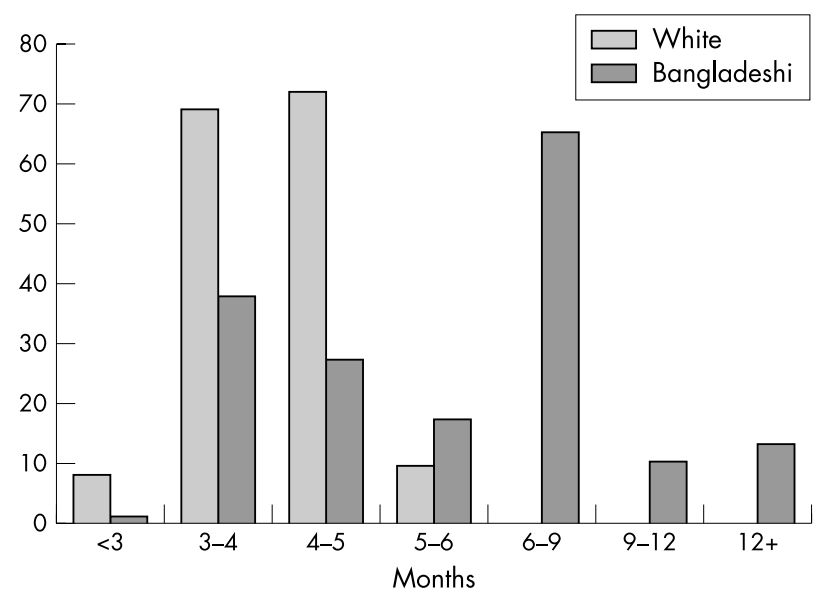

Figure 1 Age of weaning of white and Bangladeshi infants in the London Borough of Tower Hamlets. 
criteria, various prevalence rates of iron deficiency have been quoted, ranging from $15.9 \%$ in inner city Bristol ${ }^{32}$ to $9 \%$ in under $5 \mathrm{~s}$ in the USA. ${ }^{33}$ In particular, it is known that Asian children have a higher rate of iron deficiency than most other racial groups, and unofficial estimates in the London Borough of Tower Hamlets suggest that $30-40 \%$ of 2 year olds are iron deficient.

Although malabsorption and bleeding are described as causes of iron deficiency, the overwhelming cause is dietary in origin. The main reason for this high rate is the undue reliance on fresh unmodified cows' milk and non-iron containing convenience foods as a major source of nutrition rather than iron containing food. Much of this is the result of late or inappropriate weaning. It has been shown that iron intake is low in the first four years of life, but does increase after that; iron intake is lowest in families on lower incomes and in poorer areas. ${ }^{34}$

A term baby is born with sufficient iron stores for 68 months, assuming that the mother has sufficient iron stores herself. This is on the assumption of breast feeding, with the low, but available iron levels of iron in breast milk. If appropriate weaning has taken place, at 4 months of age, on to appropriate iron containing weaning foods, significant iron deficiency should not occur.

\section{Does iron deficiency matter?}

There is evidence from animal experiments that myelination is poor in rats' brains made iron depleted, and in puppies there are lower brain lipids. Iron deficiency reduces fatty acid metabolism in puppies, and reduces carnitine levelsbelieved to be essential in fatty acid metabolism. In the human child there are suggestions that there is an improvement in the developmental findings in those children receiving iron supplementation as opposed to those not receiving them. ${ }^{35}$

Even though the possibility of developmental delay is by no means universally accepted, iron is an essential nutrient with important physiological roles in early life. Severe iron deficiency anaemia does have adverse effects on psychological and mental functions; there is less evidence on whether iron deficiency in the absence of anaemia has adverse effects on neurological function. ${ }^{36}$

Children with iron deficiency seem to have language delay, poor coordination, and delayed motor skills and in those children given iron supplementation there did appear to be an improvement in skills. ${ }^{37}$ However, these findings are by no means universally seen, and in other studies using iron fortified follow on formula, iron status improved, but not development or growth. ${ }^{39}$ Accordingly, there is still uncertainty about the subject. ${ }^{40}$

In addition, children who are iron deficient tend to be shorter than non-iron deficient children, and there is some evidence that they may be more prone to more infections, although this remains speculative. ${ }^{41} 42$

A problem with all of the above is that poor growth, mild learning difficulties, and recurrent viral infections are a feature of deprived and overcrowded inner city areas, and the iron deficiency may yet be another manifestation of poor environment and diet. ${ }^{43}$

However, many of the features of apparent developmental delay could be related to the behaviour of iron deficient children. Children learn from play and interaction, and iron deficient children are always tired and clingy, and so do not interact with other children. In addition, they have a short attention span, unhappiness, and increased fearfulness ${ }^{44}$ The apparent developmental delay could be related to this "social isolation", as suggested by workers at the University of Michigan. ${ }^{45}$
Although the picture is still not clear, evidence is continuing to accumulate that chronic iron deficiency does have significant effects on cognitive development, and it would be remiss of paediatricians not to treat iron deficiency when it is detected.

\section{Prevention of iron deficiency}

Many attempts have been made to combat the high rates of iron deficiency in inner cities, most of which have only had limited and short term effects. However, studies in Birmingham showed that iron deficiency is abolished in infants who were fed with an iron fortified formula until 18 months of age. ${ }^{46}$

Clearly the most important part of prevention is to wean infants appropriately on to iron containing foods at the correct age. However, education has been shown to be ineffective, as many health professionals themselves are not clear about appropriate weaning practices, and furthermore, recent work has shown that health professionals may not be the most appropriate people to give this information. ${ }^{30}$

In the short term, if high levels of milk drinking are likely to persist, then continuation of formula feeding with standard formulae or follow on formulae (containing more iron) should be used. The use of follow on formulae has been shown to prevent iron deficiency. ${ }^{46}$ However, milk tokens to enable poor families to obtain free milk are not available beyond 1 year of age, and are not available at all for follow on formulae. In many inner city areas, as many as $60 \%$ of mothers are dependent on milk tokens.

Other options to consider are the use of tokens to enable poor families to obtain iron rich weaning foods at reduced rates, or routine iron supplementation for vulnerable infants. There is no information available on such initiatives.

\section{RICKETS}

Before the Second World War, rickets was rife in most inner cities in the UK. In those days it was caused by a combination of poor nutrition and absence of sunlight-the result of heavy industrial pollution. Rickets is still a problem in those parts of the world where there are high levels of atmospheric pollution. ${ }^{47}$ Rickets became rare in the UK following the introduction of the welfare nutrition schemes, but rickets has begun to re-emerge over the past 30 years, most especially in arrivals from India, Pakistan, and Bangladesh. ${ }^{48}$

Rickets is an ever present problem in Asian communities in inner cities in the UK. Numbers are not large, but in some boroughs about 30-40 new cases a year are seen. Although the numbers are relatively small, each case is unnecessary as rickets is preventable by appropriate vitamin supplementation.

Recent work in Tower Hamlets (awaiting publication) showed that there is confusion among health visitors and doctors about vitamin supplementation, and as a result less than half of the children who should be taking vitamin drops are not. Department of Health $(\mathrm{DOH})$ recommendations are that vitamin drops should be given from 6 months to 2 years, and until 5 years in vulnerable children. All infants over 12 months of age being breast fed or on unmodified cows' milk should be given vitamins. If health visitors and doctors are confused about DOH recommendations, it is unreasonable to expect families to ask for vitamin drops at the health clinics.

It is clear that there should be further public health campaigns, as have been done in the past, to address the continuing problems of rickets in Asian families in the UK. This should not only be targeted at families, but also at health workers, many of whom are not clear about $\mathrm{DOH}$ recommendations regarding appropriate vitamin supplementation. ${ }^{49}$ 


\section{OBESITY}

There is a virtual epidemic of obesity in the UK and it has been suggested that $15.8 \%$ of 2 year old infants are overweight and $6 \%$ obese, while at 4 years $20.3 \%$ are overweight and $7.6 \%$ obese. ${ }^{50}$ Studies in the UK have shown that for the younger child, energy intake is higher in children of manual or unskilled parents, but interestingly, overall intake had not changed much from 1967/69. ${ }^{51} 52$ However, in the older group, intake of energy has fallen slightly, but more importantly, levels of activity have fallen. More children are taken to school by car and spend a significant proportion of time playing computer games or watching television, with its diet of convenience food adverts all day long. As a result, we are now seeing rises of type II diabetes mellitus in young teenagers, particularly in children of some Asian groups with high levels of type II diabetes within the population. ${ }^{53}$ The combination of a genetic predisposition and obesity due to inertia and inappropriate food intake is a potentially lethal combination, with all the hazards of obesity with respect to long term health.

Increasing levels of obesity are leading to increases of associated problems, especially obstructive apnoea, polycystic ovary disease, joint problems, etc.

Although much of the rise in obesity is due to a high intake of carbohydrate rich convenience foods, at times the result of misplaced dietary advice, ${ }^{54}$ more fat is also being consumed in our diets. Many prepared or convenience foods have unacceptably high levels of fat. There has also been a major change in our diets in evolutionary terms, further contributing to the problems..$^{55}$

There is some evidence that obese children have a higher risk of becoming obese adults. Analysis of the 1958 British birth cohort showed that $9 \%$ of obese 33 year old women had been overweight at the age of 7 years. ${ }^{56}$ Fat children face at least a twofold greater risk of becoming obese as adults, posing significant risks to long term health. ${ }^{57}$

\section{THE FUTURE}

It is the responsibility of us all working with children to redouble our efforts to improve childhood nutrition. Evidence continues to accumulate about the dangers of iron deficiency on development. Similarly LCPUFA deficiencies may be of more long term significance than has previously been realised in the long term health and development of children.

Paediatricians, general practitioners, and health visitors have to spend a large amount of time dealing with iron deficiency and feeding difficulties, which can be traced clearly to inappropriate weaning practices and ignorance about appropriate foods to be given. A top priority should be for all community child health services to devote more time and resources to educational programmes aimed at the community, rather than at an individual level, where much of the information being imparted is not being followed. Resources should be in place to educate not only health professionals, but also to embark on intensive education of the relevant community through link workers targeting families in addition to the mother. Until such resources are in place, all paediatricians working in inner cities will continue to see the burden of not eating, iron deficient children, with the potential effects on growth and development.

However, as it seems that advice from health workers is not being adhered to, that intervention should be more specifically targeted at families by non-medical workers (for example, from within the community). Various "Sure Start" schemes are addressing such issues on a small scale, but as yet no information is forthcoming on the effects of such interventions. The model should be an educational programme to local women, who then give this information to families in the home rather than relying on health workers in clinic settings. The use of video programmes has also to be explored.

Another major priority is changes in the welfare rules, some of which are being implemented by the government in the UK. It must be made easier for mothers from poor families either to continue formula feeding beyond 12 months of age or to have follow on milks made available on their milk tokens. Although costly, that would at least reduce significantly the burden of chronic iron deficiency and give community staff more time to concentrate on appropriate feeding practices.

More controversially, attention should be paid to the advertising of convenience and fast foods on television. Cigarette adverts are banned on health grounds and the WHO banned advertising of artificial milk formulae-why not something similar for advertising such foods, particularly during children's programmes? In parallel with this should be greater efforts to encourage children to take part in activities other than watching television and playing computer games. Schools should routinely have PE and games afternoons as used to happen, and should be provided with funding to re-establish what was once a cherished tradition of the British school system.

Although much work has been done around early growth and development linked to LCPUFA, little comparable effort is being put into the considerable problems of inappropriate nutrition in the inner cities of the UK. This should be a major priority over the next few years.

Of course, our difficulties pale into insignificance compared with the massive problems in the developing world, but the fact that we see so many problems is a sad indictment of modern Western style living. At present survival rates in the western world are high-but with this legacy of chronic iron deficiency and obesity in our population, can we be sure that the survival rates of our current children will be as good in the future?

\section{REFERENCES}

1 Jain A, Concato J, Leventhal JM. How good is the evidence linking breast feeding and intelligence? Pediatrics 2002;109:1044-53.

2 Anderson JW, Johnstone BM, Remley DT. Breast feeding and cognitive development: a meta-analysis. Am J Clin Nutr 1999;70:525-35.

3 Nicoll A, Williams A. Breast feeding. Arch Dis Child 2002;87:91-2.

4 Davies DP. Adequacy of expressed breast milk for early growth of preterm infants. Arch Dis Child 1977;52:296-301.

5 Greer FR, McCormick A. Improved bone mineralisation and growth in premature infants fed fortified own mother's milk. J Pediatr 1988;112:961-9.

6 Anderson GH, Atkinson SA, Bryan MH. Energy and macronutrient content of human milk during early lactation from mothers giving birth prematurely and at term. Am J Clin Nutr 1981;34:258-65.

7 Carlson SJ, Ziegler EE. Nutrient intakes and growth of very low birth weight infants. J Perinatol 1998; 18:252-8.

8 Schanler RJ. The use of human milk for premature infants. Paediatr Clin North Am 2001;48:207-19.

9 Ostertag SG, LaGamma EF, Reisen CE, et al. Early enteral feeding does not does not affect the incidence of necrotising enterocolitis. Pediatrics 1986;77:275-80.

10 Lucas A, Bloom SR, Aynsley-Green A. Postnatal surges in plasma gut hormones in term and preterm infants. Biol Neonate 1982:41:63-7.

11 Dunn L, Hulman S, Weiner J, et al. Beneficial effects of early hypocaloric enteral feeding on neonatal gastrointestinal function: preliminary report of a randomised trial. J Pediatr 1988; 112:622-9.

12 Cooke RJ, Embleton ND. Feeding issues in preterm infants. Arch Dis Child Fetal Neonatal Ed 2000;83:F215-18.

13 Martinez M. Tissue levels of polyunsaturated fatty acids during early human development. J Pediatr 1992;120:S129-38.

14 Simopoulos AP. Omega-3 fatty acids in health and disease and in growth and development. Am J Clin Nutr 1991;54:438-63.

15 Lamptey MS, Walker BL. Learning behaviour and brain lipid composition in rats subjected to essential fatty acid deficiency during gestation, lactation and growth. J Nutr 1978;108:358-67.

16 Aggett PJ, Haschke F, Heine W, et al. Comment on the content and composition of lipids in infant formulas. ESPGAN Committee on Nutrition. Acta Paediatr Scand 1991;80:887-96.

17 Lucas A, Morley R, Cole TJ. Randomised trial of early diet in preterm babies and later intelligence quotient. BMJ 1998;317:1481-7. 
18 Gibson RA, Makrides M. Polyunsaturated fatty acids and infant visual development: a critical appraisal of randomised clinical trials. Lipids 2000;34:179-84

19 Willatts $\mathbf{P}$, Forsyth JS, DiModugno MK, et al. Effect of long-chained polyunsaturated fatty acids in infant on problem solving at 10 months of age. Lancet 1998:352:688-91.

20 Carlson SE, Cooke RJ, Rhodes PG, et al. Effect of vegetable and marine oils in preterm infant formulas on blood arachidonic and docosahexanoic acids. J Pediatr 1992; 120:S159-67.

21 Auestad N, Montalto MB, Hall RT, et al. Visual acuity, erythrocyte fatty acid composition and growth in term infants fed formulas with long chained polyunsaturated fatty acids for one year. Ross Pediatric Lipid Study. Pediatr Res 1997;41:1-10.

22 Birch EE, Hoffman DR, Uauy $R$, et al. A randomised controlled trial of early dietary supply of long-chained polyunsaturated fatty acids and mental development in term infants. Dev Med Child Neurol 2000;42:174-81.

23 Makrides M, Neumann MA, Simmer K, et al. A critical appraisal of the role of dietary long-chain polyunsaturated fatty acid on neural indices of term infants: a randomised, controlled trial. Pediatrics 2000;105:32-8.

24 Carlson SE, Cooke RJ, Werkman SH, et al. First year growth of preterm infants fed standard compared to marine oil n-3 supplemented formula. Lipids 1992;27:901-7.

25 Simmer K. Long chain polyunsaturated fatty acid supplementation in infants born at term. The Cochrane Library, Issue 1, 2003.

26 Avery A, Baxter A. "Change to cup": an audit to determine parental awareness and practices in changing from bottle to cup. J Hum Nutr Diete 2001;14:217-23.

27 Harris RJ, Armstrong D, Ali R, et al. Nutritional survey of Bangladeshi children aged under 5 in the London Borough of Tower Hamlets. Arch Dis Child 1983;58:428-32.

28 Thomas M, Avery V. Infant feeding practices in Asian families. London: Office for National Statistics, HMSO, 1997.

29 Northstone K Emmett P, Nethersole F, et al. The effect of age of introduction to lumpy solids on foods eaten and reported feeding difficulties at 6 and 15 months. J Hum Nutr Dietet $2001 ; 14: 43-54$.

30 Harris RJ. Is milk best for infants and toddlers? J Nutr Environ Med 2002;12:145-51.

31 COMA. Weaning and the weaning diet, DOH report on Health and Social Subjects 45. London: HMSO, 1994

32 James J, Evans J, Male P, et al. Iron deficiency in inner city pre-school children: development of a general practice screening programme. J R Coll Gen Pract 1988:38:250-2.

33 Looker AC, Dallman PR, Carroll MD, et al. Prevalence of iron deficiency in the United States. JAMA 1997;277:973-6.

34 Anon. National Diet and Nutrition Survey: children aged $1 \frac{1}{2}$ to $4 \frac{1}{2}$. Vol. 1 . Report of the diet and nutrition survey. London: HMSO, 1995

35 Pollitt E. Iron deficiency and cognitive function. Ann Rev Nutr 1993;13:521-37

36 Aggett PJ, Agostoni C, Axelsson I, et al. Iron metabolism and requirements in early childhood: do we know enough, A commentary by the ESPGHAN Committee on Nutrition. J Pediatr Gastroenterol Nutr 2002;34:337-45.
37 Aukett MA, Parkes YA, Scott PH, et al. Treatment with iron increases weight gain and psychomotor development. Arch Dis Child 1986;61:849-57.

38 Idjradinata $\mathrm{P}$, Pollitt $\mathrm{E}$. Reversal of developmental delays in iron deficiency in infants treated with iron. Lancet 1993:341:1-4.

39 Morley R, Abbott R, Fairweather-Tait $S$, et al. Iron fortified formula from 9 to 18 months improves iron status but not development or growth: a randomised trial. Arch Dis Child 1999;81:247-52.

40 Logan S. Commentary: Iron deficiency and developmental deficit-the jury is still out. BMJ 1999.318:697-8.

41 Walter T, Arredondo S, Arevalo M, et al. Effect of iron therapy on phagocytosis and bactericidal activity in neutrophils of iron deficient infants. Am J Clin Nutr 1986:44:877-82.

42 Thibault $H$, Galan $P$, Selz F, et al. The immune response in iron-deficient young children: effect of iron supplementation on cell-mediated immunity. Eur J Pediatr 1993;152:120-4.

43 Grantham-McGregor A, Ani C. A review of studies of the effect of iron deficiency on cognitive development in children. J Nutr $2001 ; 131: 6495-668$ S

44 Lozoff B, Brittenham GM. Behavioral alterations in iron deficiency. Haem Oncol Clin N Am 1987; 1:449-64.

45 Lozoff B, Klein NK, Nelson EC, et al. Behavior of infants with iron-deficiency anemia. Child Dev 1998;69:24-36.

46 Williams J, Wolff A, Daly A, et al. Iron supplemented formula milk related to reduction in psychomotor decline in infants from inner city areas: randomised study. BMJ 1999;318:693-7.

47 Shaw NJ, Pal BR. Vitamin D deficiency in UK Asian families: activating a new concern. Arch Dis Child 2002;86:147-9.

48 Agarwal KS, Mughal MZ, Upadhyay $P$, et al. The impact of atmospheric pollution on vitamin D status of infants and toddlers in Delhi, India. Arch Dis Child 2002;87:111-13.

49 Dunnigan MG, Glekin BM, Henderson JB, et al. Prevention of rickets in Asian children: an assessment of the Glasgow campaign. BMJ 1985;291:239-42.

50 Reilly JJ, Dorosty AA, Emmett PM. Prevalence of overweight and obesity in British children: cohort study. BMJ 1999;319:1039.

51 Anon. National Diet and Nutrition Survey: children aged 4 to 18. Vol. 1 Report of the Diet and Nutrition Survey. London: HMSO, 2000.

52 Riddoch CJ, Boreham CA. The health-related physical activity of children. Sports Med 1995; 19:86-102

53 Dabelea D, Pettitt DJ, Jones KL, et al. Type 2 diabetes mellitus in minority children and adolescents: an emerging problem. End Met Clinics 1999;28:709-29.

54 Willett WC, Stampfer MJ. Rebuilding the pyramid. Scientific American 2003:52-9.

55 Mann N. Dietary lean red meat and human evolution. Eur J Nutr 2000;39:71-9.

56 Power C, Lake J, Cole T. Measurement and long-term risks of child and adolescent fatness. Int J Obes Relat Metab Disord 1997;21:507-26.

57 Serdula $M$, Ivery D, Coates $R$, et al. Do obese children become obese adults? A review of the literature. Prev Med 1993;22:167-77.

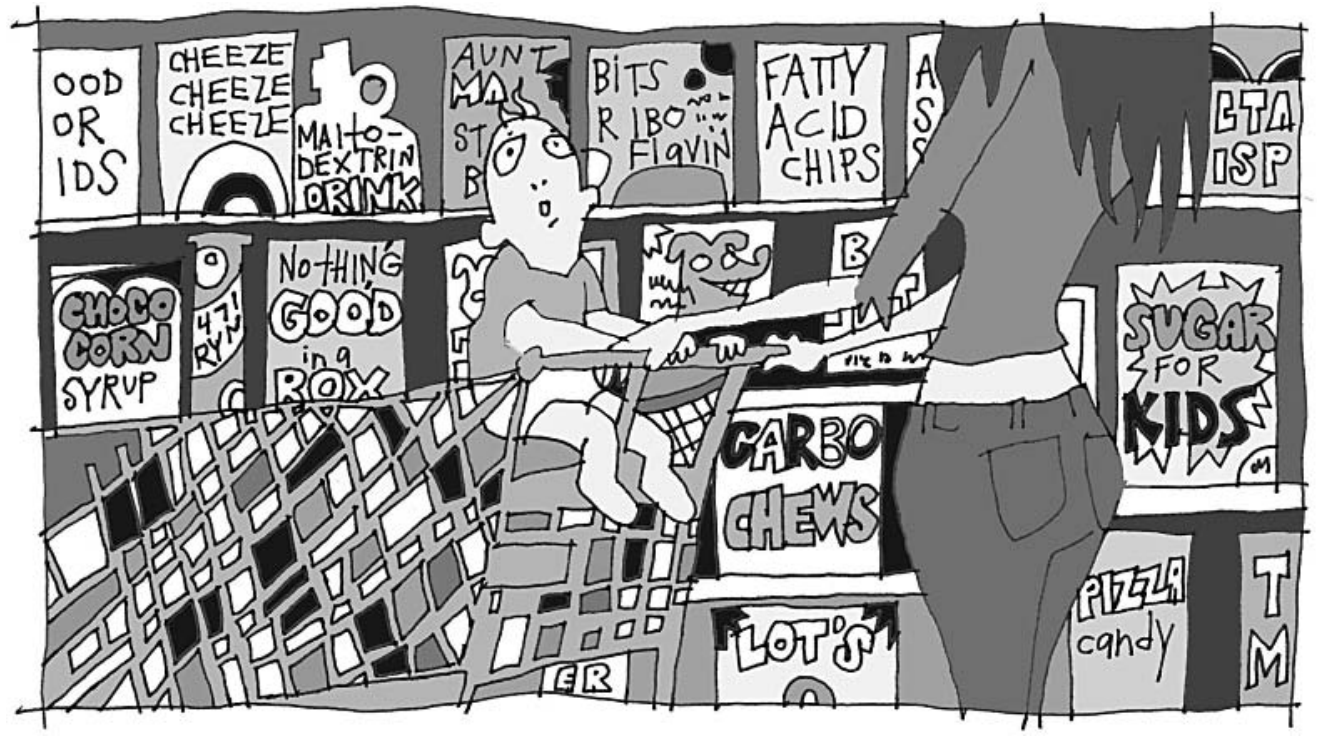

